\title{
Vouching for access
}

\author{
The US Food and Drug Administration's priority review voucher system for drugs to treat neglected disease has come \\ under scrutiny for lacking preconditions that ensure fair pricing of the products that they aim to usher forward. That \\ loophole needs to be closed.
}

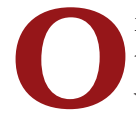
n 10 June, the US Food and Drug Administration announced that it had, for the first time in the country, approved an oral vaccine for the prevention of cholera. The product, called Vaxchora, received the agency's authorization for use in the protection of adults aged 18-64 traveling to cholera-endemic regions. The news was even more momentous because the FDA simultaneously awarded the vaccine's maker, PaxVax, a special 'priority review' voucher for future use under a government program that was originally conceived to encourage drug development for under-researched tropical diseases. At a time when these vouchers have extraordinary value, however, the program designed to award them is facing increased scrutiny and criticism, even from those who helped to initiate the voucher system.

The FDA's priority-review voucher program traces its roots back to a paper published in Health Affairs in 2006 that called for an incentive system to spur research and innovation for treatments targeting neglected tropical diseases (Health Aff. 25, 313-324, 2006). Legislation passed the next year by the US government made this a reality with the voucher program. Vouchers are awarded to companies when they secure FDA approval for drugs that are designed to treat one of more than a dozen tropical diseases, as defined by the agency, including leprosy and malaria. The vouchers can be redeemed later for a 'priority' FDA review of a different drug, a speedy process that takes around six months; without a voucher, the standard decision process can drag on for years. Notably, these vouchers can be transferred between companies. The first such sale of one of these was announced in November 2014-Knight Therapeutics said that it sold its priority-review voucher, which it had originally received in reward for the approval of a leishmaniasis drug, to Gilead Sciences for $\$ 125$ million. Other vouchers for drugs targeting tropical diseases, as well as those granted for pediatric diseases (in a related voucher system), have sold for even more money.

In December 2014, US President Barack Obama signed legislation that, among several changes, allowed vouchers received for tropicaldisease drugs to be sold an unlimited number of times. The changes also added Ebola to the list of diseases covered by the program. In April this year, the purview widened further to include Zika. But criticisms of the voucher program have grown stronger in the last year, not the least of which include calls for earlier and more systematic reviews of the pathogens that are eligible for vouchers as a way to encourage drug development in anticipation of epidemics, rather than simply in response to them.

There is also worry that certain entities can 'game' the system and reap the rewards from the voucher system without actually doing the research legwork needed to develop truly novel therapies. In December 2015, only a few weeks after he had assumed leadership of KaloBios
Pharmaceuticals, Martin Shkreli-who was arrested later that month on charges of fraud unrelated to the company-said that he had agreed to acquire the rights to benznidazole, a drug that had long been used to treat Chagas disease in affected countries but that had not yet been approved by the FDA. Shkreli told investors that the company would move the drug through the FDA process to receive a voucher and that he had hopes of pricing the drug - which is already approved in other countries-as highly as the expensive drugs used to treat hepatitis C.

Both researchers and lawmakers have taken umbrage at the fact that the voucher program has a loophole allowing drugs that have already been approved elsewhere to receive vouchers. Currently, the program does not require the company seeking a voucher for a product to have contributed to the drug's development. On 8 June, a voice vote approved an amendment (to an unrelated bill under discussion in a Congressional subcommittee) proposed by US House Representative G.K. Butterfield (Democrat, North Carolina) that would limit vouchers for tropical diseases, such that they cannot be awarded to products that have been previously approved in other countries. The update is a slight twist on a similar idea put forth a couple of years ago by Duke University scholar David Ridley, one of the authors of the 2006 Health Affairs article that seeded the idea for the voucher program. In an opinion piece in the San Francisco Chronicle in 2014, Ridley encouraged lawmakers to restrict eligibility for vouchers to new products that have not been approved anywhere else for more than two years at the time of submission of the application to the FDA.

Ridley also called for a requirement that recipients of vouchers for tropical diseases report on the affordability of their drugs and urged them to license these products to generic manufacturers in poor countries. Late last year, nonprofit groups such as Doctors Without Borders and the Drugs for Neglected Diseases Initiative began to push for the priority-review program to oblige recipients to have an access strategy for products that are awarded vouchers. The nonprofit groups point out that recipients of such vouchers are not even required to market the products that earn the vouchers. Lawmakers must act to close the loopholes in the voucher program to ensure affordability and access.

In April, KaloBios - now no longer under Shkreli-issued a press release stating that in the case of benznidazole, "the price will be cost plus a modest profit margin." It is commendable that the company is making such promises, but the priority-review voucher program for tropical diseases should ultimately not leave decisions about access and affordability wholly up to drugmakers. After all, the dialogue around medicines for neglected diseases is not only about prioritizing their regulatory review, but also about prioritizing their delivery to those who desperately need them. 